\section{BRAZIULIAN JOURNAL}

OF MEDICAL AND BIOLOGICAL RLSH.ARCH

www.bjournal.com.br
ISSN 0100-879X

Volume 43 (03) 226-324 March 2010

BIOMEDICAL SCIENCES

AND

CLINICAL INVESTIGATION

Braz J Med Biol Res, March 2010, Volume 43(3) 303-309

Radioiodine plus recombinant human thyrotropin do not cause acute airway compression and are effective in reducing multinodular goiter

C.C. Albino, H. Graf, G. Paz-Filho, L.A. Diehl, M. Olandoski, A. Sabbag and C. Buchpiguel

The Brazilian Journal of Medical and Biological Research is partially financed by
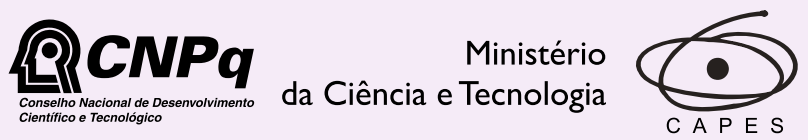

Ministério da Educação

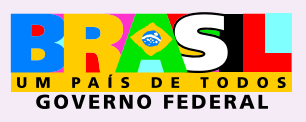

Institutional Sponsors 


\title{
Radioiodine plus recombinant human thyrotropin do not cause acute airway compression and are effective in reducing multinodular goiter
}

\author{
C.C. Albino ${ }^{1,2}$, H. Graf ${ }^{3}$, G. Paz-Filho ${ }^{3,4}$, L.A. Diehl ${ }^{5}$, M. Olandoski ${ }^{6}$, \\ A. Sabbag 6 and C. Buchpiguel ${ }^{7}$ \\ ${ }^{1}$ Instituto de Diabetes e Endocrinologia de Maringá, Maringá, PR, Brasil \\ ${ }^{2}$ Núcleo Diagnóstico de Maringá, Maringá, PR, Brasil \\ ${ }^{3}$ SEMPR - Serviço de Endocrinologia e Metabologia, Universidade Federal do Paraná, Curitiba, PR, Brasil \\ ${ }^{4}$ The John Curtin School of Medical Research, Australian National University, Canberra, Australia \\ 5 Universidade Estadual de Londrina, Londrina, PR, Brasil \\ ${ }^{6}$ Núcleo de Bioestatística, Pontifícia Universidade Católica do Paraná, Curitiba, PR, Brasil \\ ${ }^{7}$ Departamento de Radiologia, Universidade de São Paulo, São Paulo, SP, Brasil
}

\begin{abstract}
Recombinant human thyrotropin (rhTSH) reduces the activity of radioiodine required to treat multinodular goiter (MNG), but acute airway compression can be a life-threatening complication. In this prospective, randomized, double-blind, placebo-controlled study, we assessed the efficacy and safety (including airway compression) of different doses of rhTSH associated with a fixed activity of 131 I for treating MNG. Euthyroid patients with MNG $(69.3 \pm 62.0 \mathrm{~mL}, 20$ females, 2 males, $64 \pm 7$ years $)$ received 0.1 $\mathrm{mg}$ (group I, $\mathrm{N}=8$ ) or $0.01 \mathrm{mg}$ (group II, $\mathrm{N}=6$ ) rhTSH or placebo (group III, $\mathrm{N}=8$ ), $24 \mathrm{~h}$ before $1.11 \mathrm{GBq}{ }^{131}$ I. Radioactive iodine uptake was determined at baseline and $24 \mathrm{~h}$ after rhTSH and thyroid volume (TV, baseline and 6 and 12 months after treatment) and tracheal cross-sectional area (TCA, baseline and 2, 7, 180, and 360 days after rhTSH) were determined by magnetic resonance; antithyroid antibodies and thyroid hormones were determined at frequent intervals. After 6 months, TV decreased significantly in groups I $(28.5 \pm 17.6 \%)$ and II $(21.6 \pm 17.8 \%)$, but not in group III $(2.7 \pm 15.3 \%)$. After 12 months, TV decreased significantly in groups I $(36.7 \pm 18.1 \%)$ and II $(37.4 \pm 27.1 \%)$, but not in group III $(19.0 \pm 24.3 \%)$. No significant changes in TCA were observed. T3 and free T4 increased transiently during the first month. After 12 months, 7 patients were hypothyroid $(\mathrm{N}=$ 3 in group I and $\mathrm{N}=2$ in groups II and III). rhTSH plus a $1.11-\mathrm{GBq}$ fixed ${ }^{131} \mathrm{I}$ activity did not cause acute or chronic changes in TCA. After 6 and 12 months, TV reduction was more pronounced among patients treated with rhTSH plus ${ }^{131}$ I.
\end{abstract}

Key words: Hyperthyroidism; Multinodular goiter; Tracheal airway; 131I; Thyrotropin alpha

\section{Introduction}

Among many therapeutic options available for volume reduction of multinodular goiter (MNG), surgery is the treatment of choice. This approach leads to immediate reduction in thyroid volume (TV), as well as to prompt resolution of compressive symptoms. Additionally, surgery provides the opportunity for a complete histological evaluation (1). The radioactive isotope ${ }^{131}$ I can be used as an alternative when surgery is contraindicated or declined by the patient (2).

For the last two decades, radioiodine has been an effective therapy. One year after the administration of ${ }^{131}$, the reduction in TV ranges from 30 to $40 \%(2,3)$, with resolution of compressive symptoms in most patients (4). The activ- ity of radioiodine required for a significant TV reduction is positively correlated with the initial TV and inversely correlated with the 24-h radioactive iodine uptake (RAIU). In many patients with MNG, low RAIU is observed. Since most patients with MNG have large goiters and low or normal RAIU, large activities of radioactive ${ }^{131}$ I are usually required. For this reason, patients treated with ${ }^{131}$ I are often subject to hospitalization, to greater exposure to radiation, and to higher treatment costs (5).

Recent studies have shown that low doses of recombinant human thyrotropin (rhTSH) not only increase RAIU (6), but also lead to a more homogenous pattern of uptake

Correspondence: C.C. Albino, Rua Silva Jardim, 160, 87013-010 Maringá, PR, Brasil. Fax: +55-44-3028-1114.

E-mail: ccalbino@uol.com.br

Received May 3, 2009. Accepted January 7, 2010. Available online January 22, 2010. Published March 12, 2010. 
(7). Taken together, these properties reduce the ${ }^{131}$ I activity required for the treatment of MNG (8). We have demonstrated that rhTSH, at doses ranging from 0.005 to $0.2 \mathrm{mg}$, associated with $1.11 \mathrm{GBq}^{131} \mathrm{I}$, increases RAIU and leads to significant decreases in TV, with mild and readily treatable adverse effects (9-12).

Acute airway compression causing goiter swelling after the administration of rhTSH (13-15) or ${ }^{131}$ I alone $(16,17)$ can be a life-threatening complication within the first few days after treatment. Airway compression can be evaluated by measuring the tracheal cross-sectional area (TCA). However, there are no studies evaluating TCA within the first week of treatment with rhTSH plus ${ }^{131}$ I or ${ }^{131}$ I alone (18). Although treatment of MNG with rhTSH and ${ }^{131}$ I appears to be effective and safe, there are few prospective controlled studies reported in the literature.

In the present study, we determined the side effects, especially on the airways, of the treatment of euthyroid MNG with a fixed activity of ${ }^{131}$ I activity, $1.11 \mathrm{GBq}$, after the administration of placebo or low doses of rhTSH $(0.01$ or $0.1 \mathrm{mg}$ ). This is the first study to evaluate the early effects of combined rhTSH-131/ therapy (before 1 week) on TCA. In addition, we evaluated the efficacy of the proposed treatment in terms of thyroid volume reduction.

\section{Patients and Methods}

\section{Patients}

We evaluated 22 patients with MNG (20 females and 2 males; age $64 \pm 7$ years). Patients were randomly and consecutively selected from the thyroid outpatient clinic of the Maringá University, Brazil. All patients had goiters larger than $40 \mathrm{~mL}$, and either had a contraindication for surgery, or declined surgery. None of the patients had been previously submitted to surgery or to treatment with radioiodine. Prior to the treatment, malignancy was excluded by ultrasoundguided fine needle aspiration biopsy of the dominant and/ or suspect nodules and by cytology studies. None of the participants had used amiodarone or iodinated contrast in the past 12 months. Patients with TSH levels below normal were excluded. Normal levels of creatinine, transaminases and fasting glucose, as well as normal electrocardiogram, excluded the presence of comorbidities.

\section{Methods}

This was a prospective, randomized, double-blind, placebo-controlled study. Patients underwent clinical examinations and blood was drawn before treatment and on days $0,3,10,30,90,180$, and 360. On those days, we determined total triiodothyronine ( $\mathrm{T} 3$, chemiluminescence, reference range $1.23-3.30 \mathrm{nM}$, sensitivity $0.29 \mathrm{nM}$ ), free thyroxine ( $\mathrm{T} 4$, chemiluminescence, reference range 10.43-23.81 $\mathrm{pM}$, sensitivity $5.15 \mathrm{pM}$ ) and thyroid-stimulating hormone (TSH, chemiluminescence, reference range 0.4-4.0 $\mathrm{mIU} / \mathrm{L}$, sensitivity $0.004 \mathrm{mIU} / \mathrm{L}$ ). TSH receptor antibody (radioim- munoassay, reference range $<10 \mathrm{IU} / \mathrm{L}$, sensitivity $0.4 \mathrm{U} / \mathrm{L}$ ), antithyroperoxidase antibody (TPOAb, chemiluminescence, reference range $<10 \mathrm{IU} / \mathrm{mL}$, sensitivity $5 \mathrm{IU} / \mathrm{mL}$ ) and antithyroglobulin antibody (enzyme immunoassay, reference range $<20 \mathrm{IU} / \mathrm{mL}$, sensitivity $2.0 \mathrm{IU} / \mathrm{mL}$ ) were measured on days $0,90,180$, and 360 . All assays were performed with kits from DPC Diagnostics Products Corporation, USA.

Prior to the treatment, TV was measured by MRI using a 1.5-Telsa magnetic resonance system (Signa GE, 1.5 Tesla, USA), which is an accurate method for assessing TV (19). T1-weighted images were obtained from coronal, transverse and sagittal sections with $0.5 \mathrm{~mm}$ of thickness by using a neck coil. The thyroid limits were manually drawn, and the thyroid area was calculated by the built-in (dedicated) software. Thyroid volume was measured at baseline, and $2,7,180$, and 365 days after treatment with ${ }^{131} \mathrm{I}$.

Tracheal compression was indirectly estimated by determining the tracheal cross-sectional area before treatment and on days 2, 7, 180, and 360. TCA was obtained by drawing the external border of the trachea, captured through T1-weigheted transverse images.

Basal 24-h RAIU (Pho/Dot scanner, Nuclear Chicago, USA) and ${ }^{131}$ I scintigraphies (dual-headed SPECT camera, Elscint-Helix, Israel) were obtained after the oral administration of $1.85 \mathrm{MBq}^{131} \mathrm{l}$. Those evaluations were performed approximately 30 days before treatment and repeated 24 $\mathrm{h}$ after the administration of rhTSH or placebo. All patients were advised to follow a low-iodine diet, starting 2 weeks prior to the administration of the diagnostic and therapeutic activities of ${ }^{131} \mathrm{I}$.

For the treatment, a 1.1-mg vial of rhTSH (Thyrogen ${ }^{\circledR}$, Genzyme Corp., USA) was diluted with $1.2 \mathrm{~mL}$ sterile water for injection, resulting in a 1-mL drawable solution of rhTSH concentrated at $0.9 \mathrm{ng} / \mathrm{mL}$. A $1.0-\mathrm{mL}$ aliquot of this solution was then diluted with $9 \mathrm{~mL}$ sterile water for injection, which resulted in a $0.1-\mathrm{mg} / \mathrm{mL}$ solution. In order to obtain the 0.01 $\mathrm{mg} / \mathrm{mL}$ solution of $\mathrm{rhTSH}, 1 \mathrm{~mL}$ of the $0.1-\mathrm{mg}$ solution was diluted with $9 \mathrm{~mL}$ sterile water.

Twenty-four hours prior to the administration of 131 I (day 0 ), patients were assigned to a previously predefined treatment group by simple randomization (20). In that procedure, the patients were assigned directly to study and control groups, with no intermediate stages. Patients in group I received $1.0 \mathrm{~mL}$ of this solution $(0.1 \mathrm{mg} \mathrm{rhTSH})$ intramuscularly, and group II received $1.0 \mathrm{~mL}$ of the 0.01 $\mathrm{mg} / \mathrm{mL}$ solution. Group III received $1.0 \mathrm{~mL}$ isotonic saline. On the same day, a tracer activity of $1.85 \mathrm{MBq}{ }^{131}$ I was given to all patients. On the following day (day 1), RAIU and scintigraphies were obtained, and $1.11 \mathrm{GBq}{ }^{131}$ I was administered to all participants as a fixed-dose therapeutic scheme.

Adverse effects were evaluated by clinical assessment and by frequent measures of thyroid hormone levels. Patients and investigators were blind to the treatment throughout the study, including the physicians responsible for the 
interpretation of the scintigraphies, RAIU and MRI.

\section{Statistical analysis}

The Shapiro-Wilks test was used to assess normality. One-way ANOVA with repeated measures was used to compare the responses within groups and within time, in normally distributed groups. In case of significant differences between groups by one-way ANOVA, we used the LSD test for multiple comparisons within two groups. For groups without normal distribution, within-group comparisons were made with the Kruskal-Wallis test. In case of significant differences between groups by the Kruskal-Wallis test, we used the Mann-Whitney test for multiple comparisons within two groups. The Wilcoxon test was used to compare the results after treatment with those obtained at baseline. The relative changes determined by the treatment were compared within the groups by covariance analysis, with the pretreatment variable fixed as a co-variable. For dichotomous variables, the groups were compared by a model of logistic regression. Results were considered to be significant when $\mathrm{P}<0.05$. For multiple comparisons by non-parametric tests, the $P$ value was adjusted by the Bonferroni procedure.

This trial was reviewed and approved by the Ethics Committees of the Universities of Maringá and of São Paulo, Brazil, and written informed consent was obtained from all patients.

\section{Results}

\section{Baseline}

The baseline characteristics of the patients at the beginning of the study were not significantly different (Table 1).

\section{Thyroid volume}

No acute changes in TV were observed on days 2 or 7 in any of the three groups. After 7 days, TV significantly decreased by $4.0 \pm 5.8 \%$ in group I $(P=0.034)$ and did not change in group II (4.2 $\pm 8.4 \%$; $P=0.369)$. In group III, TV increased by $5.3 \pm 4.6 \%(P=0.023)$. The variations in TV were similar between groups II and III $(P=0.754)$, and both were different from group I (group I vs group II: $\mathrm{P}=0.028$; group I vs group III: $\mathrm{P}=0.009)$.

After 6 months, TV decreased significantly by $28.5 \pm 17.6 \%$ in group I $(P=0.001)$, and by $21.6 \pm 17.8 \%$ in group II $(P=0.023)$, but not in group III $(2.7 \pm 15.3 \%$; $P=0.631)$. The reductions in TV were similar between groups I and II $(P=0.437)$, and both were different from group III (group I vs group III: $\mathrm{P}=0.005$; group II vs group III: $\mathrm{P}=0.041$ ).

After 12 months, a significant decrease TV was observed in groups I and II, i.e., $36.7 \pm 18.1 \%(P=0.008)$ and $37.4 \pm 27.1 \%(P=0.004)$, respectively. In group III, the changes in TV were not significant compared to baseline $(19.0 \pm 24.3 \% ; P=0.087)$. These relative reductions were not statistically different among the groups $(P=0.237)$. The absolute values of TV are given in Table 2.

\section{Tracheal cross-sectional area}

No statistical differences between baseline and posttreatment TCA values were observed in groups I, II and III (ANOVA), and no significant differences in TCA were demonstrable on days $2,7,180$, and 360 after treatment (Table 3).

\section{RAIU}

RAIU increased from a median of $15.5 \%(4.2-55.0 \%)$ to $40.2 \%$ (27.8-61.0\%; $\mathrm{P}=0.025)$ after $0.1 \mathrm{mg}$ rhTSH in group I. In group II, RAIU increased from $27.0 \%(16.8-34.3 \%)$ to $34.2 \%(27.6-54.8 ; P=0.028)$. The post-rhTSH RAIU were

Table 1. Baseline characteristics of the patients studied, before administration of ${ }^{131}$ I plus rhTSH or ${ }^{131}$ I plus placebo.

\begin{tabular}{lccc}
\hline & Group I & Group II & Group III \\
\hline Males:females $(\mathrm{N})$ & $1: 7$ & $0: 6$ & $1: 7$ \\
Age (years) & $62(44-74)$ & $61(52-72)$ & $60(33-72)$ \\
TV $(\mathrm{mL})$ & $79.7(41.1-351.5)$ & $58.6(47.2-126.9)$ & $69.7(48.2-111.4)$ \\
RAIU $(\%)$ & $15.5(4.2-55.0)$ & $26.9(16.8-34.3)$ & $15.2(3.9-30.6)$ \\
TSH (mU/L) & $0.91(0.25-1.61)$ & $0.39(0.23-1.79)$ & $0.71(0.21-1.98)$ \\
Free T4 $(\mathrm{pM})$ & $13.90 \pm 2.83$ & $13.51 \pm 2.57$ & $13.77 \pm 2.96$ \\
Total T3 $(\mathrm{nM})$ & $2.21 \pm 0.36$ & $2.30 \pm 0.42$ & $1.95 \pm 0.41$ \\
\hline
\end{tabular}

Data are reported as means \pm SD or median (range). Group I $=0.1 \mathrm{mg} \mathrm{rhTSH}$; Group II = $0.01 \mathrm{mg}$ rhTSH; Group III = placebo. $\mathrm{rhTSH}=$ recombinant human thyrotropin; TV = thyroid volume; RAIU = radioactive iodine uptake; T3 $=$ triiodothyronine; $\mathrm{T} 4=$ thyroxine. All patients were treated with a single oral activity equal to $30 \mathrm{mCi}^{131} \mathrm{I}$, preceded by a single subcutaneous injection of rhTSH or placebo. There were no statistical differences amongst the three groups (ANOVA).

Table 2. Thyroid volume (in $\mathrm{mL}$ ) before and after treatment with rhTSH plus ${ }^{131}$ I or placebo plus ${ }^{131}$ I.

\begin{tabular}{llll}
\hline & \multicolumn{1}{c}{ Group I } & \multicolumn{1}{c}{ Group II } & \multicolumn{1}{c}{ Group III } \\
\hline Baseline & $79.7(41.1-351.5)$ & $58.6(47.2-126.9)$ & $69.7(48.2-111.4)$ \\
Day 2 & $78.0(40.5-343.9)$ & $62.8(47.1-120.8)$ & $75.3(52.2-106.9)$ \\
Day 7 & $74.9(42.8-346.9)^{\star}$ & $66.0(47.9-121.7)$ & $75.3(52.5-109.5)^{\star}$ \\
6 months & $51.3(20.8-304.7)^{\star}$ & $48.7(23.6-101.3)^{\star}$ & $66.3(42.7-110.7)$ \\
12 months & $45.8(20.5-249.5)^{\star}$ & $35.2(22.4-89.2)^{\star}$ & $54.5(25.8-106.7)^{\star}$ \\
\hline
\end{tabular}

Data are reported as median (range). See Table 1 for explanation of groups. rhTSH $=$ recombinant human thyrotropin. ${ }^{*} \mathrm{P}<0.05$ compared to baseline value (LSD test). 
not different between both groups $(P=0.220)$. For group III (placebo), no changes in RAIU were observed, with values from $15.3 \%(3.9-30.6 \%)$ to $16.2 \%(9.9-31.9 \%), P$ $=0.889$.

Before treatment, heterogeneous thyroid uptake was seen in most of the patients with MNG. After rhTSH, a more homogeneous pattern of ${ }^{131}$ I distribution was seen in groups I and II.

\section{Thyroid hormones}

At baseline, participants in all groups had similar levels of TSH, total T3 and free T4. Since the first post-treatment TSH was measured on day 3 , we were unable to identify the peak levels of TSH.

After treatment, no statistically significant changes in free T4 were observed from day 0 to day 30 in group I $(P=0.387)$. For groups II and III, peak levels of free T4

Table 3. Tracheal cross-sectional area before and after treatment with rhTSH plus ${ }^{131} \mathrm{I}$ or placebo plus ${ }^{131} \mathrm{I}$.

\begin{tabular}{lrcc}
\hline TCA $\left(\mathrm{mm}^{2}\right)$ & Group I & Group II & Group III \\
\hline Baseline & $83(50-171)$ & $130(97-161)$ & $129(82-204)$ \\
Day 2 & $103(54-160)$ & $128(75-146)$ & $125(64-209)$ \\
Day 7 & $99(48-151)$ & $125(105-145)$ & $121(75-222)$ \\
Day 180 & $119(41-149)$ & $128(108-151)$ & $119(80-203)$ \\
Day 360 & $120(40-150)$ & $135(111-160)$ & $115(90-150)$ \\
\hline
\end{tabular}

Data are reported as median (minimum-maximum). $\mathrm{rhTSH}=$ recombinant human thyrotropin; TCA = tracheal cross-sectional area in $\mathrm{mm}^{2}$. See Table 1 for explanation of groups. There were no statistical differences before and after treatment in all groups (one-way ANOVA with repeated measures). were detected on day 30 (group II: $17.63 \pm 21.9$ pM, P = 0.037; group III: $20.72 \pm 2.83$ pM, $\mathrm{P}<0.001$ ), which were significantly higher than in group $I(P=0.001$ for both comparisons; Figure 1A).

Levels of T3 increased in all groups after treatment. Group I reached peak levels of T3 on day 3 (2.92 \pm 0.81 $\mathrm{nM}, \mathrm{P}=0.004)$. In group II, peak levels of T3 were reached on day $30(2.70 \pm-0.46 \mathrm{nM}, \mathrm{P}=0.03)$. In group III, peak levels of T3 were observed on day $10(2.79 \pm 0.62 \mathrm{nM}, \mathrm{P}$ $<0.001$; Figure 1B). On the first three days, levels of free T4 and total T3 were maintained within the normal range in all groups.

\section{Adverse events}

Starting on day 90 , hypothyroidism was observed in 2 patients of 8 in group I, 3 of 6 in group II and 1 of 8 in group III. After one year, one additional patient in groups I and III developed hypothyroidism.

Mild cervical discomfort, localized pain and palpitations, suggesting actinic thyroiditis, were reported by 1 patient in each group between days 3 and 10 . Propranolol, $80 \mathrm{mg} /$ day, and nonsteroidal anti-inflammatory drugs were prescribed to those patients, with prompt and complete resolution of all symptoms.

Goiter enlargement and/or compressive symptoms with respiratory difficulty were reported at baseline by 3 participants in group I, 2 in group II and 2 in group III. Those symptoms were mild, did not cause physical limitations, and were resolved without additional interventions in all but 1 patient, who had a very large goiter at baseline $(351 \mathrm{~mL})$. One year after treatment, that patient from group I remained with the same complaints. After 360 days, in spite of obtaining significant TV reduction and relative improvement of the compressive symptoms, the participant still had a very
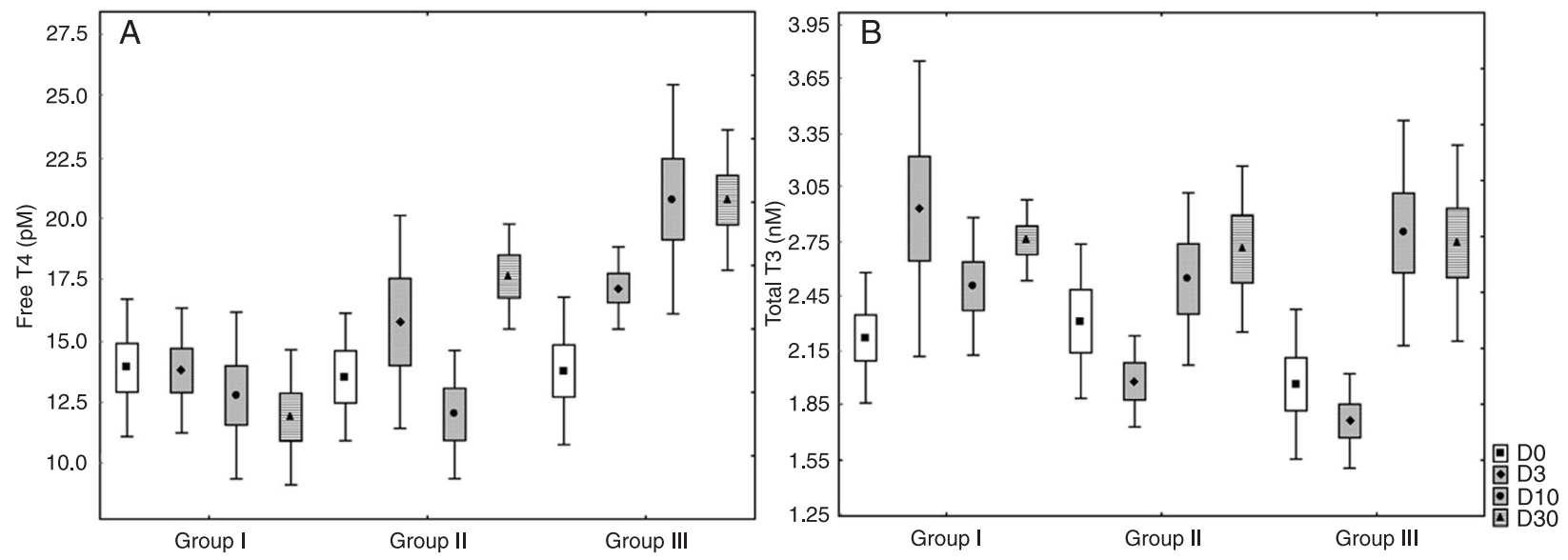

Figure 1. Changes in plasma free T4 (A) and T3 (B) after the administration of recombinant human thyrotropin (rhTSH) or placebo and radioiodine. See Table 1 for explanation of groups. The box plot indicates the $1 \pm$ SD with the point within each box being mean. The size of the rectangle indicates SD. ${ }^{*} P<0.05$, compared to baseline (ANOVA). 
large goiter $(249 \mathrm{~mL})$. Therefore, this patient was referred for a new treatment with ${ }^{131}$ I (without rhTSH).

One patient in group II and 1 patient in group III did not achieve significant TV reductions and remained with mild cervical discomfort, without respiratory symptoms. However, they preferred clinical observation with no additional treatment.

Before treatment, cosmetic complaints (discomfort due to esthetic issues) were reported by 5 patients in group I, 2 in group II, and 4 in group III. One year after treatment, only 1 patient in each group still had cosmetic complaints. Therefore, the overall satisfaction rate, regarding cosmetic complaints, was $86 \%$.

\section{Antithyroid antibodies}

Titers of TSH receptor antibody were negative for all groups throughout the study. Three new patients in group I developed TPOAb on day 90 and continued positive up to day 360 , different from groups II and III. The incidence of patients with positive antithyroid antibodies is shown in Table 4.

\section{Discussion}

In the present study, we demonstrated that treatment with ${ }^{131}$ I did not lead to acute airway obstruction, and this was independent of the administration of rhTSH. The combination of ${ }^{131} \mathrm{I}$ and $\mathrm{rhTSH}$ at 0.01 or $0.10 \mathrm{mg}$ was safe, since the incidence of adverse events was similar in all groups. In addition, treatment of MNG with ${ }^{131}$ I and rhTSH led to significant TV reduction, superior to placebo, 6 and 12 months after treatment.

Our study presents data on TCA $48 \mathrm{~h}$ after the administration of radioiodine, preceded or not by rhTSH for the first time. We did not observe significant differences in TCA after therapy, either within or between groups. This result agrees with the findings from Fast et al. (15) and from Bonnema et al. (18). However, in discordance with the latter study, we did not observe significant individual changes in TCA. Therefore, in our study, we showed that treatment with radioiodine does not influence TCA, regardless of the use of rhTSH. This could be explained by the lack of correlation between TCA and TV, also observed by Bonnema et al. (18).

In patients with MNG, rhTSH increases RAIU and determines a more homogenous distribution of radioiodine $(7,8)$, which allows a reduction in the activity of ${ }^{131} \mathrm{I}$ administered (8). Treatment of MNG with ${ }^{131}$ I alone leads to decreases in TV by 30 to $40 \%$ after 12 months (2-4). Studies evaluating the effects of rhTSH as an adjuvant to fixed activities of ${ }^{131}$ I have shown more pronounced TV reductions ranging from $34 \%$ in the first 6 months (21), to $58 \%$ in the first year (22). Even with a very low dose, we have demonstrated that rhTSH was safe and effective (10). In double-blind, randomized, placebo-controlled studies that used adjusted
Table 4. Incidence of patients with positive titers of antithyroid antibodies before and after treatment with rhTSH plus ${ }^{131}$ I or placebo plus ${ }^{131}$ I.

\begin{tabular}{ccccc}
\hline & Day 0 & Day 90 & Day 180 & Day 360 \\
\hline TgAb & 2 & 4 & 4 & 3 \\
Group I & 1 & 0 & 1 & 1 \\
Group II & 1 & 2 & 2 & 1 \\
Group III & 1 & & & \\
TPOAb & 0 & 1 & 4 & 4 \\
Group I* & 1 & 1 & 1 & 1 \\
Group II & 0 & 0 & 0 & 1 \\
Group III & 0 & 0 & 0 & 0 \\
TRAb & 0 & 0 & 0 & 0 \\
Group I & 0 & & & \\
Group II & 0 & & & \\
Group III & 0 & & & \\
\hline
\end{tabular}

Data are reported as absolute numbers. See Table 1 for explanation of groups. TRAb = thyrotropin receptor antibody; TPOAb = antithyroperoxidase antibody; TgAb = antithyroglobulin antibody. ${ }^{*} \mathrm{P}<0.05$, group I vs groups II and III for TPOAb at 90, 180 and 360 days (Kruskal-Wallis test).

activities of ${ }^{131} \mathrm{I}$, TV reductions ranged between 53 (23) and $62 \%(24)$, which were significantly greater in the groups that received rhTSH when compared to placebo.

In our study, TV reduction, compared to baseline, was significantly higher among rhTSH-treated patients, at both 6 and 12 months. Our findings agree with previous studies that evaluated goiter reduction with rhTSH and ${ }^{131} \mathrm{I}$. In those studies, goiter reduction was more significant in patients treated with rhTSH plus ${ }^{131}$ I compared to those treated with ${ }^{131}$ I alone. However, in terms of relative changes in TV, there was no difference between groups at the 12th month. This finding can be attributed to the relatively small and heterogeneous sample.

No significant transient increases in TSH were observed, with unexpectedly low peak levels in all groups. Had TSH been measured on day 2 , higher TSH levels could have been observed. Significant peak levels of free T4 were observed only in groups II and III. This suggests that the increase in free T4 may be attributed more importantly to the actinic effect of radioiodine than to the stimulatory effect of rhTSH. Significant increases in T3 were observed in all groups, with higher levels in the groups that received rhTSH. This suggests that rhTSH leads to more pronounced changes in T3 than in free T4. The timing of the T3 peaks is explainable by the rhTSH (D3 in group I) vs the actinic effect of ${ }^{131}$ I (D1030 in groups II and III). The changes in thyroid hormones should be interpreted with caution due to the heterogeneity regarding thyroid function at baseline. Nevertheless, the mean changes in thyroid hormones remained within normal ranges during the study in all groups. 
In agreement with the results of a previous study (21), our data suggest that rhTSH does not increase the incidence of hypothyroidism when compared to placebo, probably because we used low doses of rhTSH. However, other studies obtained different results $(22,24)$.

The incidence of thyrotoxic symptoms was equally distributed among the three groups. Those symptoms were mild and readily treatable with beta-blockers and nonsteroidal anti-inflammatory drugs. Since the incidence of symptomatic thyrotoxicosis was very low, we do not advocate the use of prophylactic beta-blockers.

The changes in TPOAb suggest that a higher dose of rhTSH may elicit a stronger, earlier and transient immunological response, in contrast with the results reported by Rubio et al. (25). In their study, the TPOAb surge after ${ }^{131}$ I occurred independently of the rhTSH dose.

We chose the highest outpatient radioactivity of ${ }^{131}$ I that is permitted by the Brazilian regulatory agencies. Patients receiving more than $1.11 \mathrm{GBq}$ need to be hospitalized. By administering $1.11 \mathrm{GBq}$, the need for hospitalization was eliminated and the success rates were maximized.

Our study has some limitations. First, although this was a randomized study, our sample size provided a less-thanoptimal statistical power. This could have led to the absence of difference in TV reduction at the 12th month between groups. Second, we have included some patients with relatively high RAIU, who could have been treated without the need for rhTSH. Third, we did not assess iodine intake in our patients, which could have compromised our findings

\section{References}

1. Hegedus L, Bonnema SJ, Bennedbaek FN. Management of simple nodular goiter: current status and future perspectives. Endocr Rev 2003; 24: 102-132.

2. Hegedus L, Hansen BM, Knudsen N, Hansen JM. Reduction of size of thyroid with radioactive iodine in multinodular non-toxic goitre. BMJ 1988; 297: 661-662.

3. Nygaard B, Hegedus L, Gervil M, Hjalgrim H, Soe-Jensen P, Hansen JM. Radioiodine treatment of multinodular non-toxic goitre. BMJ 1993; 307: 828-832.

4. Huysmans DA, Hermus AR, Corstens FH, Barentsz JO, Kloppenborg PW. Large, compressive goiters treated with radioiodine. Ann Intern Med 1994; 121: 757-762.

5. Huysmans DA, Buijs WC, van de Ven MT, van den Broek WJ, Kloppenborg PW, Hermus AR, et al. Dosimetry and risk estimates of radioiodine therapy for large, multinodular goiters. J Nucl Med 1996; 37: 2072-2079.

6. Huysmans DA, Nieuwlaat WA, Erdtsieck RJ, Schellekens AP, Bus JW, Bravenboer B, et al. Administration of a single low dose of recombinant human thyrotropin significantly enhances thyroid radioiodide uptake in nontoxic nodular goiter. J Clin Endocrinol Metab 2000; 85: 3592-3596.

7. Nieuwlaat WA, Hermus AR, Sivro-Prndelj F, Corstens FH, Huysmans DA. Pretreatment with recombinant human TSH changes the regional distribution of radioiodine on thyroid scintigrams of nodular goiters. J Clin Endocrinol Metab if adherence to the diet was low. This confounding factor could have been eliminated by measuring urinary iodine, a procedure that was not undertaken due to logistic issues. Fourth, it is known that rhTSH leads to maximum stimulation of the expression of the $\mathrm{Na}^{+} / \mathrm{I}^{-}$symporter 24 to $72 \mathrm{~h}$ after its injection (26). Possibly, in our study, the post-rhTSH RAIU was underestimated, since the tracer activity of ${ }^{131}$ I was administered only $2 \mathrm{~h}$ after rhTSH. A strength of our study is the homogeneous sample investigated, consisting only of euthyroid patients. In spite of these limitations, the design of our study proved to be practical and easily applicable in a clinical setting.

In this controlled study, we observed that the use of rhTSH as an adjuvant to a fixed $1.11 \mathrm{GBq}$ activity of ${ }^{131}$ I for the treatment of MNG is safe, without acute airway compression, and with mild to transient adverse effects. rhTSH enhances TV reduction 6 months and 1 year after treatment. Larger studies are needed to confirm whether the superiority of rhTSH plus ${ }^{131}$ I persists after a prolonged follow-up.

\section{Acknowledgments}

G. Paz-Filho received consulting fees from Genzyme do Brasil. This study was partially funded by Genzyme do Brasil. Genzyme do Brasil did not have any involvement in the study design, data collection, data analysis, manuscript preparation, and/or publication decisions.
2001; 86: 5330-5336

8. Nieuwlaat WA, Huysmans DA, van den Bosch HC, Sweep CG, Ross HA, Corstens FH, et al. Pretreatment with a single, low dose of recombinant human thyrotropin allows dose reduction of radioiodine therapy in patients with nodular goiter. J Clin Endocrinol Metab 2003; 88: 3121-3129.

9. Albino CC, Mesa CO Jr, Olandoski M, Ueda CE, Woellner LC, Goedert CA, et al. Recombinant human thyrotropin as adjuvant in the treatment of multinodular goiters with radioiodine. J Clin Endocrinol Metab 2005; 90: 2775-2780.

10. Cubas ER, Paz-Filho GJ, Olandoski M, Goedert CA, Woellner LC, Carvalho GA, et al. Recombinant human TSH increases the efficacy of a fixed activity of radioiodine for treatment of multinodular goitre. Int J Clin Pract 2009; 63: 583-590.

11. Paz-Filho GJ, Mesa CO, Carvalho GA, Goedert CA, Graf H. Recombinant human TSH associated with radioiodine does not have further effects on thyroid volume and function after 2 years. Clin Endocrinol 2008; 69: 345-346.

12. Paz-Filho GJ, Mesa-Junior CO, Olandoski M, Woellner LC, Goedert CA, Boguszewski CL, et al. Effect of $30 \mathrm{mCi}$ radioiodine on multinodular goiter previously treated with recombinant human thyroid-stimulating hormone. Braz J Med Biol Res 2007; 40: 1661-1670.

13. Nielsen VE, Bonnema SJ, Hegedus L. Effects of $0.9 \mathrm{mg}$ 
recombinant human thyrotropin on thyroid size and function in normal subjects: a randomized, double-blind, cross-over trial. J Clin Endocrinol Metab 2004; 89: 2242-2247.

14. Nielsen VE, Bonnema SJ, Hegedus L. Transient goiter enlargement after administration of $0.3 \mathrm{mg}$ of recombinant human thyrotropin in patients with benign nontoxic nodular goiter: a randomized, double-blind, crossover trial. J Clin Endocrinol Metab 2006; 91: 1317-1322.

15. Fast S, Nielsen VE, Bonnema SJ, Hegedus L. Dose-dependent acute effects of recombinant human TSH (rhTSH) on thyroid size and function. Comparison of $0.1,0.3$ and $0.9 \mathrm{mg}$ of rhTSH. Clin Endocrinol 2009 [Epub ahead of print; doi: 10.1111/j.1365-2265.2009.03650.x].

16. Bonnema SJ, Bertelsen H, Mortensen J, Andersen PB, Knudsen DU, Bastholt L, et al. The feasibility of high dose iodine 131 treatment as an alternative to surgery in patients with a very large goiter: effect on thyroid function and size and pulmonary function. J Clin Endocrinol Metab 1999; 84: 3636-3641.

17. Nygaard B, Faber J, Hegedus L. Acute changes in thyroid volume and function following ${ }^{131}$ I therapy of multinodular goitre. Clin Endocrinol 1994; 41: 715-718.

18. Bonnema SJ, Nielsen VE, Boel-Jorgensen H, Grupe P, Andersen PB, Bastholt L, et al. Recombinant human thyrotropin-stimulated radioiodine therapy of large nodular goiters facilitates tracheal decompression and improves inspiration. J Clin Endocrinol Metab 2008; 93: 3981-3984.

19. Huysmans DA, de Haas MM, van den Broek WJ, Hermus AR, Barentsz JO, Corstens FH, et al. Magnetic resonance imaging for volume estimation of large multinodular goitres: a comparison with scintigraphy. Br J Radiol 1994; 67: 519-523.
20. Pocock SJ. Clinical trials. A practical approach. Brisbane: John Wiley \& Sons; 1989.

21. Cohen O, llany J, Hoffman C, Olchovsky D, Dabhi S, Karasik A, et al. Low-dose recombinant human thyrotropin-aided radioiodine treatment of large, multinodular goiters in elderly patients. Eur J Endocrinol 2006; 154: 243-252.

22. Silva MN, Rubio IG, Romao R, Gebrin EM, Buchpiguel C, Tomimori $\mathrm{E}$, et al. Administration of a single dose of recombinant human thyrotrophin enhances the efficacy of radioiodine treatment of large compressive multinodular goitres. Clin Endocrinol 2004; 60: 300-308.

23. Bonnema SJ, Nielsen VE, Boel-Jorgensen H, Grupe P, Andersen PB, Bastholt L, et al. Improvement of goiter volume reduction after $0.3 \mathrm{mg}$ recombinant human thyrotropinstimulated radioiodine therapy in patients with a very large goiter: a double-blinded, randomized trial. J Clin Endocrinol Metab 2007; 92: 3424-3428.

24. Nielsen VE, Bonnema SJ, Boel-Jorgensen H, Grupe P, Hegedus L. Stimulation with 0.3-mg recombinant human thyrotropin prior to iodine 131 therapy to improve the size reduction of benign nontoxic nodular goiter: a prospective randomized double-blind trial. Arch Intern Med 2006; 166: 1476-1482.

25. Rubio IG, Perone BH, Silva MN, Knobel M, Medeiros-Neto G. Human recombinant TSH preceding a therapeutic dose of radioiodine for multinodular goiters has no significant effect in the surge of TSH-receptor and TPO antibodies. Thyroid 2005; 15: 134-139.

26. Nielsen VE, Bonnema SJ, Hegedus L. The effects of recombinant human thyrotropin, in normal subjects and patients with goitre. Clin Endocrinol 2004; 61: 655-663. 